\title{
New Anticoagulants for the Prevention and Treatment of Venous Thromboembolism
}

\author{
Joo Hee Kim ${ }^{1,2}$, Kyung-Min Lim ${ }^{2, *}$ and Hye Sun Gwak ${ }^{2, *}$ \\ ${ }^{1}$ College of Pharmacy \& Institute of Pharmaceutical Science and Technology, Ajou University, Suwon 16499, \\ ${ }^{2}$ College of Pharmacy, Ewha Womans University, Seoul 03760, Republic of Korea
}

\begin{abstract}
Anticoagulant drugs, like vitamin $\mathrm{K}$ antagonists and heparin, have been the mainstay for the treatment and prevention of venous thromboembolic disease for many years. Although effective if appropriately used, traditional anticoagulants have several limitations such as unpredictable pharmacologic and pharmacokinetic responses and various adverse effects including serious bleeding complications. New oral anticoagulants have recently emerged as an alternative because of their rapid onset/offset of action, predictable linear dose-response relationships and fewer drug interactions. However, they are still associated with problems such as bleeding, lack of reversal agents and standard laboratory monitoring. In an attempt to overcome these drawbacks, key steps of the hemostatic pathway are investigated as targets for anticoagulation. Here we reviewed the traditional and new anticoagulants with respect to their targets in the coagulation cascade, along with their therapeutic advantages and disadvantages. In addition, investigational anticoagulant drugs currently in the development stages were introduced.
\end{abstract}

Key Words: Anticoagulant, Vitamin K antagonist, Heparin, Venous thromboembolism

\section{INTRODUCTION}

Venous thromboembolism (VTE) refers to thrombosis within the vein, commonly in the legs or pelvis (deep vein thrombosis, DVT) and its complication, pulmonary embolism (PE), the condition of thrombi departing from their original generation site into a pulmonary artery (Hyers, 1999). It is the third leading cause of cardiovascular-related deaths, following acute coronary syndrome and stroke (Piazza and Goldhaber, 2010), with an annual incidence of 1 to 3 times per 1,000 people (Heit et al., 2016; Puurunen et al., 2016). Moreover, it often leads to long-term complications such as post-thrombotic syndrome and chronic thromboembolic pulmonary hypertension, which impose a significant burden on both patients and the healthcare systems (Ruppert et al., 2010; Bruni-Fitzgerald, 2015).

Pathologic thrombosis or bleeding may occur whenever the hemostatic balance is disturbed due to various health conditions including surgery, trauma, malignancy, and congenital disorders (Previtali et al., 2011) and even following chronic cigarrete smoking (Park et al., 2016). In normal circumstances, hemostasis is maintained through the complex interactions between the vascular system (Kwon et al., 2016), coagulation system, fibrinolytic system (Lee et al., 2015) and platelets (Kim et al., 2016). Natural anticoagulants such as tissue factor pathway inhibitors (TFPI), protein C, protein $\mathrm{S}$, and anti-thrombin (AT) also regulate the coagulation process. The fibrinolytic system plays a role by dissolving the fibrin clot during the healing process of an injured blood vessel (Weitz, 1997; Chapin and Hajjar, 2015).

Anticoagulants can inhibit thrombosis by altering various pathways within the coagulation system or through targeting thrombin directly by attenuating its generation (Mega and Simon, 2015). For many years, unfractionated heparins (UFHs) and vitamin $\mathrm{K}$ antagonists (VKAs) have been the main options for the prevention and treatment of VTE (Franchini et al., 2016). The treatment changed little until low molecular weight heparins (LMWHs), fragments of UFHs, were introduced in the 1980 s, simplifying the management of thromboembolism by saving the trouble of frequent coagulation monitoring (Weitz, 1997). In the 2000s, ultra-low molecular heparins (ULMWHs) were developed in an effort to improve the pharmacokinetic profile of conventional heparin formulations and to lower the

\section{Open Access https://doi.org/10.4062/biomolther.2016.271}

This is an Open Access article distributed under the terms of the Creative Commons Attribution Non-Commercial License (http://creativecommons.org/licenses/by-nc/4.0/) which permits unrestricted non-commercial use, distribution, and reproduction in any medium, provided the original work is properly cited.
Received Dec 11, 2016 Revised Jan 21, 2017 Accepted Jan 26, 2017 Published Online Apr 6, 2017

\section{*Corresponding Authors}

E-mail: kmlim@ewha.ac.kr (Lim KM), hsgwak@ewha.ac.kr (Gwak HS) Tel: +82-2-3277-3055 (Lim KM), +82-2-3277-4376 (Gwak HS) Fax: +82-2-3277-3760 (Lim KM), +82-2-3277-2851 (Gwak HS) 
<smiles>CC(=O)CC(c1ccccc1)c1c(O)c2ccccc2oc1=O</smiles>

Warfarin<smiles>O=C(NC[C@@H]1CN(c2ccc(N3CCOCC3=O)cc2)C(=O)O1)c1ccc(Cl)s1</smiles>

Rivaroxaban

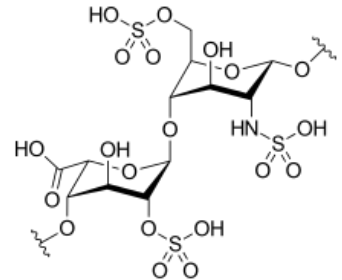

Heparin<smiles>COc1ccc(-n2nc(C(N)=O)c3c2C(=O)N(c2ccc(N4CCCCC4=O)cc2)CC3)cc1</smiles>

Apixaban<smiles>[R]OC(=O)CCN(C(=O)c1ccc2c(c1)nc(CNc1ccc(/C(N)=N/C(=O)OC)cc1)n2[R])c1ccccn1</smiles>

Dabigatran<smiles>COc1ccc(-n2nc(C(N)=O)c3c2C(=O)N(c2ccc(N4CCCCC4=O)cc2)CC3)cc1</smiles>

Edoxaban

Fig. 1. Chemical structures of current anticoagulants.

Table 1. Traditional and novel anticoagulants in the market and development

\begin{tabular}{|c|c|c|c|}
\hline Generic Name & Mechanism of action & Reversal agents & Anticoagulation monitoring \\
\hline \multicolumn{4}{|l|}{ Traditional drugs } \\
\hline Warfarin & $\begin{array}{l}\text { Deplete coagulation factors II VII, IX, and X through } \\
\text { inhibition of cyclic interconversion of vitamin } \mathrm{K} \text { and its epoxide }\end{array}$ & Vitamin $\mathrm{K}$ & INR \\
\hline UFH & $\begin{array}{l}\text { Indirectly inhibit thrombin (factor II), factor X, IX, XI, and XII via } \\
\text { enhancing the activity of antithrombin }\end{array}$ & Protamine sulfate & PT, aPTT \\
\hline LMWH & $\begin{array}{l}\text { Inhibit thrombin and factor } \mathrm{X} \text { via enhancing the activity of } \\
\text { antithrombin }\end{array}$ & Protamine sulfate & Anti-Xa assay \\
\hline ULMWH & Inhibit factor $X$ via enhancing the activity of antithrombin & - & Anti-Xa assay \\
\hline \multicolumn{4}{|l|}{ New drugs } \\
\hline Dabigatran & Inhibit free and fibrin-bound thrombin via direct binding & Idarucizumab & aPTT, ECT \\
\hline Rivaroxaban & Inhibit free and fibrin-bound factor Xa via direct binding & Andexanet alfa, PER977 & Anti-Xa assay \\
\hline Apixaban & Inhibit free and fibrin-bound factor Xa via direct binding & Andexanet alfa, PER977 & Anti-Xa assay \\
\hline Edoxaban & Inhibit free and fibrin-bound factor Xa via direct binding & Andexanet alfa, PER977 & Anti-Xa assay \\
\hline \multicolumn{4}{|c|}{ Drugs under development } \\
\hline Tifacogin & Inhibit tissue factor-factor VIla complex & - & - \\
\hline TB-402 & Inhibit factor VIII via direct binding & - & - \\
\hline Pegnivacogin & Inhibit factor IX via direct binding & - & - \\
\hline Factor XI-ASO & Inhibit factor XI via direct binding & - & - \\
\hline rHA-infestin-4 & Inhibit factor XII & - & - \\
\hline Recomodulin & $\begin{array}{l}\text { Inhibit factor } \mathrm{V} \text { and VIII via activating protein } \mathrm{C} \text { through } \\
\text { thrombin-thrombomodulin complex }\end{array}$ & - & - \\
\hline
\end{tabular}

aPTT: activated partial thromboplastin time, ASO: antisense oligonucleotide, INR: international Normalized Ratio, ECT: ecarin clotting time, LMWH: low molecular weight heparin, PT: Prothrombin time, UFH: unfractionated heparin, ULMWH: ultra-low molecular weight heparin.

risk of heparin-induced thrombocytopenia (HIT) (Masuko and Linhardt, 2012). However, all forms of heparin require parenteral administration, which is cumbersome for long-term use (Fareed et al., 2008). Similarly, oral VKAs have several drawbacks including a wide range of food and drug interactions, as well as the need for frequent monitoring and dose adjustment
(Hirsh et al., 2007).

Over the past decades new oral anticoagulants (NOACs), which more directly and selectively target specific proteins in the coagulation cascade, have been developed, as shown in Fig. 1. They are conveniently administered in oral, fixed doses without routine monitoring and have fewer interactions than 
VKAs with foods or drugs (Mekaj et al., 2015). But NOACs have their own limitations such as lack of reliable coagulation monitoring methods and selective antidotes (except dabigatran), as shown in Table 1. This review summarizes the pharmacologic characteristics of traditional and new anticoagulants, as well as anticoagulants under development, focusing on their advantages and disadvantages.

\section{TRADITIONAL ANTICOAGULANTS}

\section{Vitamin $\mathrm{K}$ antagonists}

VKAs such as coumarin derivatives (e.g., warfarin, acenocoumarol, and phenprocoumon) exert their anticoagulant effects by interfering with the cyclic interconversion of vitamin $\mathrm{K}$ and its 2,3 epoxide (KO), therefore depleting the vitamin $\mathrm{K}$ hydroquinone $\left(\mathrm{KH}_{2}\right.$; Wessler and Gitel, 1986). The coagulation factors II (thrombin), VII, IX, and X, as well as proteins C and $S$, require carboxylation, by converting glutamic acid to gamma-carboxyglutamic acid, for their normal functions. The carboxylation procedure requires $\mathrm{KH}_{2}$ (Ageno et al., 2012). VKAs inhibit vitamin $\mathrm{K}$ epoxide reductase complex 1 (VKORC1), an enzyme that catalyzes the reduction of $\mathrm{KO}$ to vitamin $\mathrm{K}$, which is then converted to $\mathrm{KH}_{2}$ and then oxidized back to $\mathrm{KO}$, concomitantly with gamma-glutamyl carboxylation. The full anticoagulation effect of warfarin is not achieved until the clearance of factor $X$ and prothrombin that have half-lives of 36 and 50 h, respectively (Loke et al., 2012). Because proteins C and S, with relatively short half-lives, initially exert their procoagulant effects, the combined use of VKAs with parenteral agents is required.

The anticoagulant response to warfarin is largely affected by diet, concurrent drugs, and genetic polymorphisms (Hirsh et al., 2003). The anticoagulant effect of warfarin can be counteracted by vitamin $\mathrm{K}$ intake either through food or supplements. A large amount of vitamin $\mathrm{K}$ causes warfarin resistance for up to a week because vitamin $\mathrm{K}$ accumulated in the liver can bypass VKORC (Lurie et al., 2010). The cytochrome P450 enzyme (CYP2C9) is responsible for oxidative metabolism of the warfarin S-isomer, which is five times more potent than the $\mathrm{R}$-isomer. Therefore, the dose-response of warfarin can be influenced by CYP2C9 inhibiting drugs that affect the metabolic clearance of warfarin, especially the S-isomers, such as phenylbutazone, sulfinpyrazone, metronidazole, trimethoprim-sulfamethoxazole, or amiodarone. It is also influenced by genetic polymorphisms in CYP2C9 and VKORC unit 1 genes (Fung et al., 2012). The individuals who carry CYP2C9*2 or CYP2C9*3 tend to have higher levels of S-warfarin due to the impaired ability to metabolize it. Since CYP2C9 is also responsible for the metabolism of acenocoumarol, and less importantly for phenprocoumon, polymorphisms of CYP2C9 also affect the efficacy of acenocoumarol and phenprocoumon, although with a lesser extent than with warfarin (Verhoef et al., 2014). Genetic mutations or an altered expression of the VKORC1 gene can also lead to variable responses, either hyper-sensitivity or resistance to warfarin therapy. Acenocoumarol and phenprocoumon are also influenced by the VKORC1 genotype, especially in the first few months.

Hemorrhage is the most significant and frequent complication related to warfarin, with an annual incidence of major bleeding at a rate of 13 per 100 patients (Linkins et al., 2003). The risk of bleeding associated with warfarin is related not only to the degree of anticoagulation but also to patient-related factors and the concurrent use of antiplatelet agents or other drugs (Fitzmaurice et al., 2002). Bleeding complications can be managed by administering vitamin $\mathrm{K}$, fresh frozen plasma (FFP), prothrombin complex concentrates (PCCs), or recombinant factor VIla (Tran et al., 2013), which can antagonize the effects of warfarin therapy.

\section{Heparins}

Heparins indirectly inhibit thrombin by enhancing the activity of antithrombin (AT), a proteinase inhibitor of coagulation enzymes such as thrombin and factors $\mathrm{Xa}$ of the common pathway, as well as IXa, Xla and XIla of the intrinsic coagulation pathway (Hirsh and Raschke, 2004). Following a conformational change induced by heparin, AT irreversibly inhibits thrombin via binding its active site. For inactivation of thrombin, heparin must bind simultaneously to thrombin at exosite 2 and AT, forming a ternary complex which requires at least 18 saccharide units (Liaw et al., 2001). In contrast, heparin only binds to AT via high-affinity pentasaccharides, for the inhibition of factor $\mathrm{Xa}$, without requiring a bridge between factor Xa and AT. Since most heparin molecules are at least 18 units long, inhibitory activities of heparin against the thrombin and factor Xa are equivalent (Hirsh, 1991). However, the ATbound heparin weakly inhibits the thrombin, once formed as a ternary heparin-fibrin-thrombin complex, because it can no longer gain access to the exosite 2 already occupied. Furthermore, AT-bound heparin is unable to inhibit factor Xa bound to activated platelets (Teitel and Rosenberg, 1983).

Unfractionated heparins (UFH): Unfractionated heparin (UFH) is heterogeneous in terms of molecular size, anticoagulant activity and pharmacokinetics (Garcia et al., 2012). The molecular weight of UFH ranges from 3,000 to $30,000 \mathrm{Da}$, with an average of $15,000 \mathrm{Da}$ (approximately 45 saccharide units). Only $20-50 \%$ of UFH chains contain the high-affinity pentasaccharide unit necessary for activating AT (Marmur, 2002). Heparin molecules without a pentasaccharide unit have minimal activity at therapeutic concentrations. Low-affinity heparin can inhibit thrombin via heparin cofactor (Tollefsen et al., 1982) as well as factor Xa generation, through AT-independent mechanisms (Garcia et al., 2012).

Besides the multiple anticoagulant mechanisms, heparin involves multiple clearance mechanisms including both rapid, saturable and slow, non-saturable processes (Hirsh and Fuster, 1994). The rapid phase of heparin clearance occurs through binding to macrophages and endothelial cells at saturable sites on the cell membrane and subsequent depolymerization, whereas the slow clearance mechanism is through the kidneys. Because low doses of heparins initially undergo the saturable and dose-dependent clearance, the effect of heparin is not linear, although both intensity and duration of heparin activity may increase with escalating doses. As a result, the pharmacokinetics and pharmacodynamics of UFH are unpredictable.

Additionally, UFH has a number of limitations such as a short duration of action with a half-life of $60 \mathrm{~min}$, poor bioavailability after subcutaneous injection, and an immune-mediated reaction, a life-threatening adverse event (Krishnaswamy et al., 2010). Heparin complexes with an endogenous platelet factor 4 (PF4), which undergoes conformational changes and becomes immunogenic, leading to the generation of heparinPF4 antibodies (Kreimann et al., 2014). The heparin-PF4-IgG 
immune complex then activates platelets and causes the release of microparticles, platelet consumption and peripheral thrombocytopenia, and also endothelial injury and activation (Rauova et al., 2006). Heparin's affinity for PF4 depends on molecular weights and chain lengths (Amiral et al., 1995), thus accounting for the increased incidence of thrombocytopenia by UFH when compared with LMWH.

The effect of UFH can be reversed by intravenously administering protamine sulfate that binds to heparin and forms a stable salt (Greinacher et al., 2015). This can be advantageous in situations of cardiac surgery or treating critically ill patients who may require rapid reversal of the anticoagulation effect.

Low molecular weight heparins (LMWH): LMWH is a mixture of polymers with molecular weights that vary from 1,000 to $10,000 \mathrm{Da}$, with a mean molecular weight between 4,000 and $5,000 \mathrm{Da}$, approximately one third the size of UFH (Hirsh, 1998). Since LMWHs are prepared by various chemical or physical depolymerizations of heparin, each LMWH has unique characteristics in terms of molecular weight, polysaccharide chain length distributions, and pharmacological properties that may influence pharmacokinetic properties and anticoagulant activity profiles (Merli and Groce, 2010). Since 50 to $75 \%$ of LMWH species have a length of less than 18 saccharides, which will inhibit only factor $\mathrm{Xa}$, the selectivity ratio of activity against factor $\mathrm{Xa}$ to thrombin varies between $4: 1$ and $2: 1$, depending on their preparations (Holmer et al., 1986). Because LMWH mostly undergoes renal elimination, its biologic half-life may be prolonged in cases of renal insufficiency, especially for those with lower molecular weights such as enoxaparin or nadroparin (Schmid et al., 2009).

In addition to the convenience of subcutaneous administration and almost $100 \%$ subcutaneous bioavailability, LMWH has several advantages over UFH in terms of pharmacological characteristics (Hirsh and Raschke, 2004). The low protein binding of LMWH makes anticoagulant effects more predictable, which allows for a fixed or body weight-based dose regimen without the need for frequent monitoring (Hirsh and Raschke, 2004). Low nonspecific binding to macrophages and endothelial cells increases the plasma half-life of LMWH. In addition, the lower binding to platelets, PF4 and osteoclasts may reduce the risk of HIT and osteoporosis.

Unlike UFH's complete neutralization activity of anti-factor $\mathrm{Xa}$, protamine sulfate reverses only about $60 \%$ of the antifactor Xa activity of LMWH (Wolzt et al., 1995). This may be due to the fact that protamine favors the regions of larger heparin chains, and an effective antidote for the residual smaller chains in LMWHs is not available (Schroeder et al., 2011). Furthermore, the subcutaneous administration of heparins is more difficult to completely reverse.

Ultra-low molecular weight heparins (ULMWHs): Ultralow molecular weight heparins (ULMWHs), also known as an indirect factor $\mathrm{Xa}$ inhibitors, are synthetic analogues of the pentasaccharide contained within heparins, with an average molecular weight of less than 3,000 Da (Walenga and Lyman, 2013). These small, homogeneous drugs have been developed on the basis that higher selectivity in the activity against factor Xa or thrombin would produce similar or better efficacy than LMWHs, but have a lower risk of bleeding and HIT. ULMWHs also exhibit anticoagulant efficacy through the selective inhibition of factor $\mathrm{Xa}$ via the unique pentasaccharide unit (Hirsh, 1998).

ULMWHs only exhibit the anti-factor Xa effect when binding to AT and are devoid of other functional components of heparins such as the release of TFPI from the vascular endothelium, the formation of complexes with PF4, and profibrinolytic actions. It is likely that the heparin chains must be of a sufficient length to form a complex with PF4 for binding to antibodies, which is a pathological mechanism of HIT (Rauova et al., 2005). Besides anticoagulant activity which is weaker than that of UFH or LMWHs, ULMWHs show anti-angiogenic, anti-metastatic and anti-inflammatory activities (Gandhi and Mancera, 2010).

The hepatic clearance of heparin is believed to involve the stabilin-2-receptor that requires heparin chains longer than decasaccharides for binding (Pempe et al., 2012). Therefore, unlike UFH, ULMWHs never reach the size needed for hepatic clearance and therefore depend heavily on renal clearance (Rupprecht and Blank, 2010).

ULMWHs offer several advantages over conventional heparins such as a higher bioavailability, rapid onset of action with longer biological half-lives, and a lower risk of bleeding, as well as osteoporosis. Because of the absence of binding to other plasma proteins, ULMWHs have predictable pharmacokinetics with almost $100 \%$ bioavailability. However, no antidote is available for bleeding associated with ULMWHs, whereas protamine sulfate can neutralize UFH completely and LMWHs partially. Unlike the impermeability of LMWHs or UFHs through the placental or blood-brain barrier, ULMWHs are able to partially pass the blood-brain barrier (Hoppensteadt et al., 2003).

\section{NEW ANTICOAGULANTS}

The newer anticoagulants offer superior therapeutic control over coagulations with minimal bleeding complications. They directly target either thrombin or factor $\mathrm{Xa}$ in the coagulation cascade, which is pharmacologically distinct from traditional anticoagulant agents (Fig. 2). Since the amount of activated coagulation factors is amplified at each level of the coagulation cascade, direct inhibition of the final products from both the intrinsic and extrinsic coagulation pathways (factor $\mathrm{Xa}$ and thrombin) can provide more effective anticoagulation.

\section{Direct thrombin inhibitors}

Thrombin is an end product in the coagulation cascade, which converts soluble fibrinogen to insoluble fibrin. It amplifies coagulation by activating factors $\mathrm{V}$ and VIII on the surface of platelets and platelet-bound factor $\mathrm{XI}$, stimulating platelets and generating more thrombin. By activating XIII, it also accelerates the formation of cross-linked fibrins and clot stabilization. In addition to its procoagulant role, thrombin plays a role in growth factor synthesis, cell proliferation, prostaglan$\operatorname{din} I_{2}$ synthesis, and chemotaxis of polymorphonuclear cells (Coughlin, 1994). Therefore, inhibition of thrombin may provide benefits in addition to anticoagulation (Bea et al., 2006).

The antithrombotic action of heparin occurs through binding to both AT and thrombin's exosite 2, a heparin-binding domain, simultaneously. Heparin also can act as a bridge between fibrin and thrombin, enhancing thrombin's affinity for fibrin and increasing the amount of fibrin-bound thrombin. Because the fibrin-heparin-thrombin complex, therefore, occupies not only 


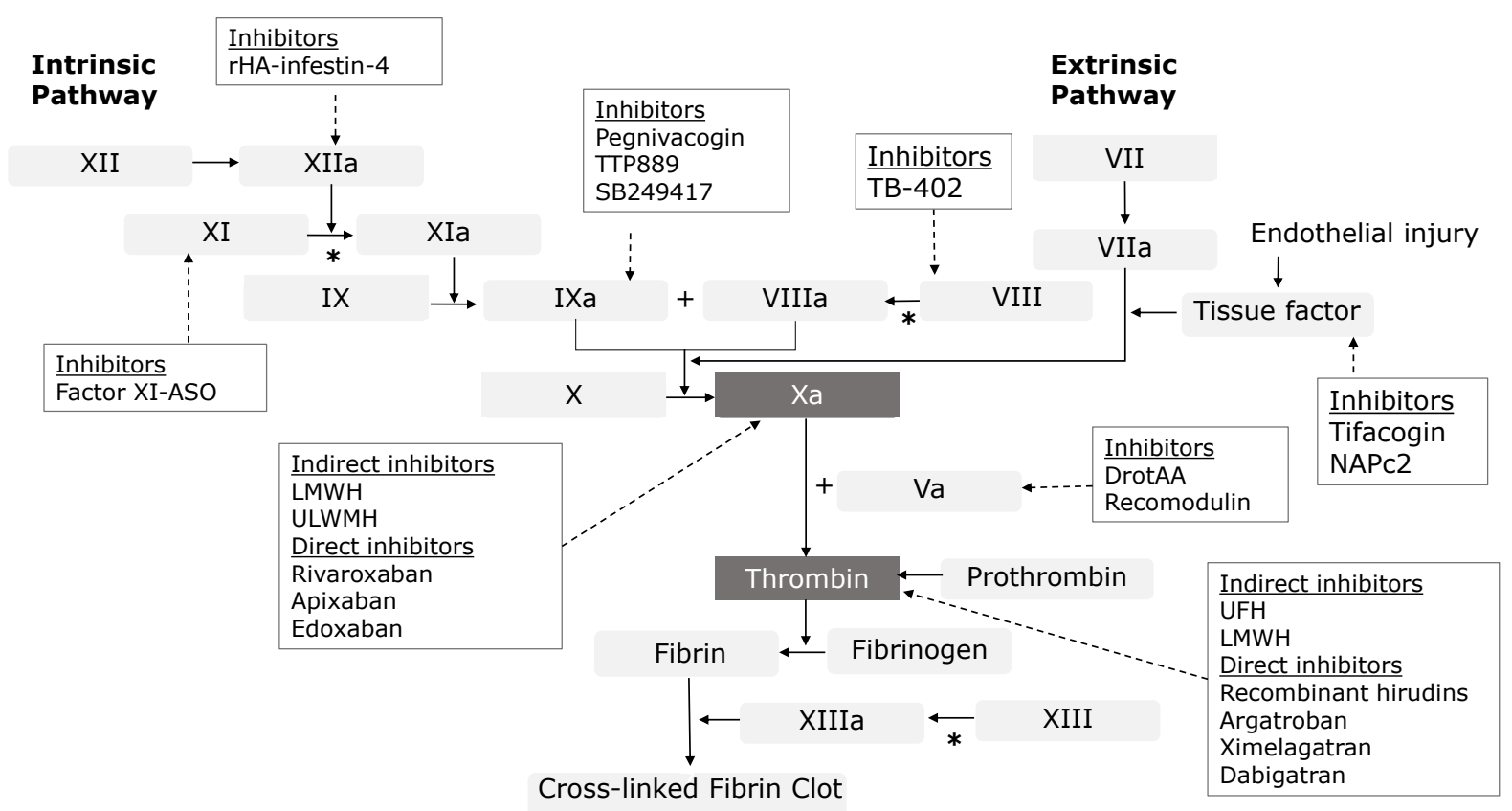

Fig. 2. Targets of various anticoagulants in the coagulation pathways. VKA: vitamin $\mathrm{K}$ antagonists, UFH: unfractionated heparin, LMWH: low molecular weight heparin, ULMWH: ultra-low molecular weight heparin, NAP: nematode anticoagulant protein, ASO: antisense oligonucleotide, DrotAA: drotecogin alpha (activated), "catalyzed by thrombin.

exosite 2 but also exosite 1 (fibrin-binding site), fibrin-bound thrombin is protected from inhibition by the heparin-AT complex and remains active, resulting in further thrombus generation (Weitz et al., 1990). As such, heparin is relatively ineffective at inhibiting thrombin propagation (Di Nisio et al., 2005).

Unlike heparins, direct thrombin inhibitors (DTIs) act without a preceding interaction with AT and directly suppress thrombin, as well as its interaction with its substrates (Di Nisio et al., 2005). DTIs block the action of thrombin by binding to the catalytic site (univalent) or to both the catalytic site and exosite 1 (bivalent) (Bates and Weitz, 2000). Therefore, DTIs can inhibit both free and fibrin-bound thrombin. In addition, there are other advantages such as more predictable anticoagulant effects due to the absence of interaction with plasma proteins, not being neutralized by PF4, the inhibition of thrombin-induced platelet aggregation and absence of immune-mediated thrombocytopenia (Lee and Ansell, 2011).

Bivalent DTIs include recombinant hirudins (e.g., lepirudin and desirudin) and a synthetic hirudin, bivalirudin (Di Nisio et al., 2005). Bivalent DTIs form an irreversible complex with thrombin, but bivalirudin, which is slowly cleaved by thrombin once bound, restores the catalytic function of thrombin (Lee and Ansell, 2011). As a result, thrombin inhibition using bivalirudin is temporary, which may contribute to its low bleeding risk compared with recombinant hirudins (Nawarskas and Anderson, 2001). Bivalirudin is mainly cleared by proteolysis and hepatic metabolism, whereas recombinant hirudins predominantly undergo renal excretion.

Univalent DTIs, such as argatroban, ximelagatran, and dabigatran exteilate, non-covalently and reversibly bind to thrombin, leaving a small fraction of free thrombin (Di Nisio et al., 2005). Reversible and selective binding to thrombin accompanies a minimal risk of bleeding and rapid restoration of hemostasis to baseline upon discontinuation. Like recombinant hirudins, argatroban is a parenteral DTI but is metabolized by the liver (Koster et al., 2007).

Ximelagatran, a prodrug of melagatran, is the first oral DTI, which represents a new era of anticoagulation for the prevention and treatment of VTE. Although it was withdrawn from the market due to a risk of significant hepatotoxicity, ximelagatran demonstrated improved antithrombotic efficacy when compared with traditional anticoagulation therapies (Evans et al., 2004). A few years later, dabigatran etexilate, the second oral DTI, was developed with some improvements such as no risk of hepatotoxicity and low potential for food or drug interactions. Following oral absorption, dabigatran etexilate is rapidly converted into its active form, dabigatran, by nonspecific serum esterase without the involvement of cytochrome P450 enzymes or other oxidoreductases. Therefore, dabigatran etexilate has a low potential for interacting with drugs (Stangier and Clemens, 2009). Approximately $80 \%$ of circulating dabigatran is excreted unchanged via the kidneys and the remainder is conjugated with glucuronic acid. The conjugated dabigatran, which exhibits similar properties to the unconjugated form, is predominantly excreted via the bile.

Currently, none of the DTIs, except dabigatran, have direct reversal agents available for use. Recombinant factor VIla, activated prothrombin complex concentrate (aPCC), activated charcoal, desmopressin and von Wilebrand factor concentrate have been tried in various studies (Majeed and Schulman, 2013; Baumann Kreuziger et al., 2014). Dabigatran effects can be reversed within minutes of intravenous administration of idarucizumab, a humanized monoclonal antibody, which binds tightly and prevents dabigatran from binding to thrombin (Sie, 2016). 


\section{Direct factor Xa inhibitors}

Factor $\mathrm{Xa}$ is a primary site of amplification for coagulation factors, generating about 1,000 thrombin molecules from a single Xa molecule (Mann et al., 2003). Factor Xa binds to negatively charged phospholipid surfaces, which are exposed on activated platelets, together with factor Va to form the prothrombinase complex, the activator that converts prothrombin into thrombin. The conversion of fibrinogen to fibrin, the basic building block of all blood clots, is then catalyzed by thrombin. The rate of prothrombin activation by factor $\mathrm{Xa}$ in a prothrombinase complex is dramatically increased, thereby rapidly facilitating thrombin generation and plug formation at sites of injury. Whereas heparin inhibits factor Xa and thrombin to a similar degree, LMWHs have a relatively greater inhibitory effect against factor $\mathrm{Xa}$, which has drawn attention as a potential anticoagulant target (Garcia et al., 2012). The interest of factor Xa as a drug target was further solidified by positive results from the use of fondapariunux, a parenteral indirect factor Xa inhibitor (Yeh et al., 2012).

Unlike indirect factor $\mathrm{Xa}$ inhibitors which are dependent on AT, direct factor $\mathrm{Xa}$ inhibitors interact directly and selectively with factor $\mathrm{Xa}$ and inhibit both free and bound forms of factor Xa without affecting platelet aggregation (Rupprecht and Blank, 2010). They are also associated with reduced incidence of rebound thrombosis compared to direct and indirect thrombin inhibitors (Perzborn et al., 2011). Because direct factor Xa inhibitors have good bioavailability with rapid onset of action, there is no need for bridging therapy with a parenteral agent (Cabral and Ansell, 2015). In general, they exhibit linear pharmacokinetics and display predictable anticoagulation effects following oral administration. All three agents, rivaroxaban, apixaban, and edoxaban, are excreted through the kidneys to varying degrees and have elimination half-lives much shorter than the VKAs. Rivaroxaban has a dual mechanism of excretion, with two-thirds of the administered dose excreted through the urine as either unchanged or inactive metabolites and one-third of the dose excreted through feces (Perzborn et al., 2011). Only $25 \%$ of an apixaban dose is eliminated by the kidneys with the remainder excreted via the fecal route (Eriksson et al., 2009). Edoxaban undergoes multiple elimination pathways with $35 \%$ excreted in the urine. Over $70 \%$ of the dose is excreted unchanged (Bounameaux and Camm, 2014).

The substantial benefits of oral factor Xa inhibitors are unfortunately accompanied by a high incidence of major and clinically relevant bleeding including gastrointestinal bleeding (Connolly and Spyropoulos, 2013). Moreover, all three factor Xa inhibitors are CYP3A4 and P-glycoprotein (P-gp) substrates that carry potential drug interaction issues. The CYP3A4 and/or P-gp inhibitors, as well as inducers, might impact the concentration of oral factor Xa inhibitors, leading to increased risk of bleeding or thrombosis (Short and Connors, 2014).

Potential antidotes for reversing anticoagulation caused by factor Xa inhibitors are currently under development (Ahmed et al., 2016). Andexanet alfa is a recombinant, modified factor Xa protein with a mutation on the catalytic site that abolishes the procoagulant property, which binds to direct and indirect factor Xa inhibitors in the blood (Connors, 2015). PER977 (e.g., arapazine and ciraparantag) binds to factor Xa inhibitors, as well as direct and indirect thrombin inhibitors, through noncovalent bonds and electrical charge interactions (Das and Liu, 2015).

\section{ANTICOAGULANTS UNDER DEVELOPMENT}

Both thrombin and factor Xa inhibitors have been extensively evaluated in several large clinical trials for the prevention and treatment of thromboembolic disorders. Despite their excellent efficacy compared to traditional agents, these drugs have their own drawbacks. Bleeding is still a major issue, with no reliable diagnostic test available to safely monitor the therapeutic dosage, as well as a lack of effective reversal agents (Hyers, 1999; Miller et al., 2012; Hu et al., 2016).

A variety of anticoagulant strategies, targeting other steps in coagulation, are in development to attempt to overcome the limitations of currently used agents. Drugs that target the tissue factor (TF)-factor VIla complex inhibit the initiation of coagulation. Propagation of coagulation can be inhibited by drugs that target factors IXa or Xa or by agents that inactivate their respective cofactors, factors VIIla and Va.

\section{Tissue factor pathway inhibitors}

Following vascular injury, TF, also known as thromboplastin, is exposed to the blood and binds to factor VIla, which sets off the extrinsic coagulation pathway (Wood et al., 2014). The TF-factor VIla complex activates factors X and IX. Additionally, activated factor IX forms a complex with factor VIIla, which also activates factor $X$. Factor $X a$ then binds to factor $V a$ to form prothrombinase, an enzymatic complex which rapidly converts prothrombin to thrombin. The TF activity and the extrinsic pathway are regulated by the tissue factor pathway inhibitor (TFPI). It inhibits factor Xa directly and the TF-factor VIla complex in an Xa-dependent fashion. The factor Xa-dependent inhibition of the TF-factor VIla complex generates an inactive quaternary complex in the plasma membrane.

Inhibition of TF-factor VIla complex by recombinant TFPI was examined in various models of disseminated intravascular coagulation such as sepsis. Tifacogin, a recombinant TFPI expressed in Saccharomyces cerevisae, inhibits factor VIla in a factor Xa-dependent fashion (Matyal et al., 2005). The drug requires intravenous infusion since the drug has a short plasma half-life and easily eliminated by the liver. The benefits of tifacogin administration in sepsis, pneumonia, and bacteremia have been investigated without promising results (Abraham et al., 2003; Hardy et al., 2006; Laterre et al., 2009). The synthetic nematode anticoagulant protein (NAPc2), which was originally isolated from the canine hookworm Ancylostoma canimum, binds to a non-catalytic site on factor $\mathrm{Xa}$ to form a NAPc2-factor-Xa complex and inhibits factor VIla from binding to TF (Vlasuk and Rote, 2002). Because of its high affinity binding, NAPc2 has a half-life of about $50 \mathrm{~h}$ after subcutaneous administration. Factor VIla with its active site blocked competes with factor VIla for TF binding sites, thereby attenuating the initiation of coagulation by the TF-factor VIla complex (Dickinson and Ruf, 1997)

\section{Factor VIII inhibitors}

Factor VIII (i.e., anti-hemophilic factor) acts as a cofactor for factor IXa, which activates factor X, thereby, forming an amplification loop (Lenting et al., 1998). Partial inhibition of factor VIII appears to be essential to reduce the risk of bleeding because complete inhibition will induce pathological hemophilia. 
TB-402 is a recombinant human monoclonal antibody that binds with a high affinity to factor VIII, partially inhibiting the action of factor VIII (Verhamme et al., 2010). It is under phase 2 clinical trials and the exact target of factor VIII inhibition and the degree of inhibition need to be established in further research.

\section{Factor IXa inhibitors}

The TF-factor VIla complex activates factor IX, which is relatively stable and diffuses toward activated platelets (Howard et al., 2007). The activated platelets then bind the factor VIIa-IXa complex and recruit factor $X$ for its activation. The activation of factor $\mathrm{X}$ by the factor VIla-IXa complex is nearly 50 times more efficient than the TF-factor VIla complex (Butenas et al., 2002). Therefore, factor IXa represents a prime target for anticoagulation. Defects in factor IXa lead to hemophilia B, while increased concentrations of factor IXa in the blood result in a significantly increased risk of thrombosis formation.

Factor IXa inhibitors including factor IX-directed monoclonal antibodies, factor IXa-directed RNA aptamers (e.g., pegnivacogin), and oral factor IXa inhibitors (e.g., TTP889) have been investigated in humans. SB249417, a chimeric monoclonal antibody directed against the factor IXa, completed a phase I clinical trial, showing a dose-dependent effect on clotting times after continuous infusion (Chow et al., 2002). The REG1 system consisted of pegnivacogin (RB006) and anivamersen (RB007), its complementary control agent being an aptamerbase factor IXa inhibitor that is being investigated for acute coronary syndrome (Vavalle and Cohen, 2012). Aptamers are small oligonucleotides with high affinity that are used as active drugs. Partial inhibition using TTP889 was not an effective strategy for VTE prophylaxis and TTP889 is currently being investigated for advanced heart failure to determine the potential benefit of attenuated thrombin generation (Roser-Jones et al., 2011). Natural factor IX binding proteins and factor IXai are under pre-clinical trials.

\section{Factor XI inhibitors}

A study showed that factor XI deficiency was associated with a less severe bleeding tendency and a lower incidence of venous thrombosis and stroke, compared to deficiencies of factors VIII or IX, which suggests factor XI is a safe target for anticoagulation. Factor XI inhibition has been extensively studied in both arterial and venous thrombosis in diverse animal models. Antibodies and antisense oligonucleotides (FXI-ASO) against factor XI both showed protective effects in thrombosis without an increased risk of bleeding (Büller et al., 2015). The anti-human factor XI monoclonal antibody was used to prevent vascular graft occlusion in a primate thrombosis model. Similar studies are currently being conducted to ensure the safety of factor XI inhibitors in humans.

\section{Factor XII inhibitors}

Available data on factor XII was limited but factor XII knockout mice were observed to have protection against pathologic thrombosis while having no hemostasis changes. The selective factor XIla inhibitor, recombinant human albumin fused to the factor XIla inhibitor infestin-4 (rHA-infestin-4), was developed (Hagedorn et al., 2010). Inhibition of factor XII is apparently a safe and efficient way of thrombosis prevention, at least in animals. Factor XII antisense, Pro-Phe-Arg-chloromethylketone, Ir-CPI, and several non-specific protein inhibi- tors are under pre-clinical trials.

\section{Factor Va inhibitors}

Factor $\mathrm{V}$ acts as a cofactor of factor $\mathrm{Xa}$ and forms a prothrombinase complex, together with platelet membrane phospholipids. Factor Va inhibitors include drotecogin alpha (activated; DrotAA) and Recomodulin (ART-123), which were initially developed for sepsis-induced thrombosis treatment. DrotAA is a recombinant form of activated protein $\mathrm{C}$ with antithrombotic, anti-inflammatory and pro-fibrinolytic properties (Dellinger, 2003). It showed some beneficial effects for coagulation abnormalities associated with severe sepsis but failed to show improvement of patients with severe sepsis. As of 2011, DrotAA was withdrawn from the market.

Recomodulin, a recombinant human thrombomodulin alpha, has shown to be efficacious for VTE prophylaxis following total hip replacement surgery and sepsis-associated disseminated intravascular coagulation (DIC) (Kearon et al., 2005; Vincent et al., 2013). Thrombomodulin is a thrombin receptor and the thrombin-thrombomodulin complex activates protein $\mathrm{C}$ to form activated protein $\mathrm{C}$, which inactivates factors Va and VIIIa (Esmon, 2005). It has a long plasma half-life after a subcutaneous injection of two to three days, such that it can be given once every five to six days to maintain anticoagulant activity.

\section{Polyphosphate inhibitors}

Polyphosphate is a polymer of inorganic phosphate residues and is secreted by activated platelets and mast cells. It may initiate and/or accelerate coagulation, acting at several points in the coagulation cascade (Ruiz et al., 2004). It accelerates the activation of factor $\mathrm{V}$, as well as factor XI by thrombin, and enhances fibrin clot structure increasing its resistance to fibrinolysis (Smith and Morrissey, 2008; Smith et al., 2012). A variety of compounds that inhibit polyphosphate and reduce thrombosis are under investigation in animal disease models. Universal heparin reversal agent (UHRA) compounds were studied in mouse models of thrombosis and hemostasis to ensure reduced toxicity and bleeding risk, compared to the toxic substances such as polyethylenimine, polyamidoamine dendrimers, and polymyxin B (Travers et al., 2014).

\section{CONCLUSIONS}

The prevention and treatment of VTE is evolving. The new target-specific oral anticoagulants such as oral DTIs and direct factor Xa inhibitors have shifted a paradigm from hospitals to outpatient settings exempting drug monitoring. Current oral anticoagulants available offer predictable, reversible anticoagulant effects with no need for invasive monitoring. However, the major complication of these drugs, bleeding, especially gastrointestinal bleeding, continues to persist, and an optimal management strategy needs to be provided. To date, different categories of anticoagulants are currently under development with unique profiles, along with benefits and potential drawbacks. In the future, the search for safer and more effective oral anticoagulants that have an antidote for rapid reversal will continue. 


\section{ACKNOWLEDGMENTS}

This work is supported by the National Research Foundation of Korea (Grant No. NRF-2015R1D1A1A01057931).

\section{REFERENCES}

Abraham, E., Reinhart, K., Opal, S., Demeyer, I., Doig, C., Rodriguez, A. L., Beale, R., Svoboda, P., Laterre, P. F., Simon, S., Light, B., Spapen, H., Stone, J., Seibert, A., Peckelsen, C., De Deyne, C., Postier, R., Pettilä, V., Sprung, C. L., Artigas, A., Percell, S. R., Shu, V., Zwingelstein, C., Tobias, J., Poole, L., Stolzenbach, J. C. and Creasey, A. A. (2003) Efficacy and safety of tifacogin (recombinant tissue factor pathway inhibitor) in severe sepsis: A randomized controlled trial. JAMA 290, 238-247.

Ageno, W., Gallus, A. S., Wittkowsky, A., Crowther, M., Hylek, E. M. and Palareti, G. (2012) Oral anticoagulant therapy: antithrombotic therapy and prevention of thrombosis, 9th ed: American college of chest physicians evidence-based clinical practice guidelines. Chest 141, e44S-e88S.

Ahmed, Z., Hassan, S. and Salzman, G. A. (2016) Novel oral anticoagulants for venous thromboembolism with special emphasis on risk of hemorrhagic complications and reversal agents. Curr. Drug Ther. 11, 3-20.

Amiral, J., Bridey, F., Wolf, M., Boyer-Neumann, C., Fressinaud, E., Vissac, A. M., Peynaud-Debayle, E., Dreyfus, M. and Meyer, D. (1995) Antibodies to macromolecular platelet factor 4-heparin complexes in heparin-induced thrombocytopenia: a study of 44 cases. Thromb. Haemost. 73, 21-28.

Bates, S. M. and Weitz, J. I. (2000) The mechanism of action of thrombin inhibitors. J. Invasive Cardiol. 12 Suppl F, 27F-32.

Baumann Kreuziger, L. M., Keenan, J. C., Morton, C. T. and Dries, D. J. (2014) Management of the bleeding patient receiving new oral anticoagulants: A role for prothrombin complex concentrates. BioMed Res. Int. 2014, 583794

Bea, F., Kreuzer, J., Preusch, M., Schaab, S., Isermann, B., Rosenfeld, M. E., Katus, H. and Blessing, E. (2006) Melagatran reduces advanced atherosclerotic lesion size and may promote plaque stability in apolipoprotein E-deficient mice. Arterioscler. Thromb. Vasc. Biol. 26, 2787-2792.

Bounameaux, H. and Camm, A. J. (2014) Edoxaban: an update on the new oral direct factor Xa inhibitor. Drugs 74, 1209-1231.

Bruni-Fitzgerald, K. R. (2015) Venous thromboembolism: an overview. J. Vasc. Nurs. 33, 95-99.

Butenas, S., Brummel, K. E., Branda, R. F., Paradis, S. G. and Mann, K. G. (2002) Mechanism of factor VIla-dependent coagulation in hemophilia blood. Blood 99, 923-930.

Büller, H. R., Bethune, C., Bhanot, S., Gailani, D., Monia, B. P., Raskob, G. E., Segers, A., Verhamme, P. and Weitz, J. I. (2015) Factor $\mathrm{XI}$ antisense oligonucleotide for prevention of venous thrombosis. N. Engl. J. Med. 372, 232-240.

Cabral, K. P. and Ansell, J. E. (2015) The role of factor Xa inhibitors in venous thromboembolism treatment. Vasc. Health Risk Manage. $11,117-123$.

Chapin, J. C. and Hajjar, K. A. (2015) Fibrinolysis and the control of blood coagulation. Blood Rev. 29, 17-24.

Chow, F. S., Benincosa, L. J., Sheth, S. B., Wilson, D., Davis, C. B. Minthorn, E. A. and Jusko, W. J. (2002) Pharmacokinetic and pharmacodynamic modeling of humanized anti-factor IX antibody (SB 249417) in humans. Clin. Pharmacol. Ther. 71, 235-245.

Connolly, G. and Spyropoulos, A. C. (2013) Practical issues, limitations, and periprocedural management of the NOAC's. J. Thromb. Thrombolysis 36, 212-222.

Connors, J. M. (2015) Antidote for factor Xa anticoagulants. N. Engl. J. Med. 373, 2471-2472.

Coughlin, S. R. (1994) Thrombin receptor function and cardiovascular disease. Trends Cardiovasc. Med. 4, 77-83.

Das, A. and Liu, D. (2015) Novel antidotes for target specific oral anticoagulants. Exp. Hematol. Oncol. 4, 25.

Dellinger, R. P. (2003) Inflammation and coagulation: Implications for the septic patient. Clin. Infect. Dis. 36, 1259-1265.

Dickinson, C. D. and Ruf, W. (1997) Active site modification of factor VIla affects interactions of the protease domain with tissue factor. J. Biol. Chem. 272, 19875-19879.

Di Nisio, M., Middeldorp, S. and Büller, H. R. (2005) Direct thrombin inhibitors. N. Engl. J. Med. 353, 1028-1040.

Eriksson, B. I., Quinlan, D. J. and Weitz, J. I. (2009) Comparative pharmacodynamics and pharmacokinetics of oral direct thrombin and factor Xa inhibitors in development. Clin. Pharmacokinet. 48, 1-22.

Esmon, C. T. (2005) The interactions between inflammation and coagulation. Br. J. Haematol. 131, 417-430.

Evans, H. C., Perry, C. M. and Faulas, D. (2004) Ximelagatran/melagatran. Drugs 64, 649-678.

Fareed, J., Hoppensteadt, D. A., Fareed, D., Demir, M., Wahi, R., Clarke, M., Adiguzel, C. and Bick, R. (2008) Survival of heparins, oral anticoagulants, and aspirin after the year 2010. Semin. Thromb. Hemost. 34, 58-73.

Fitzmaurice, D. A., Blann, A. D. and Lip, G. Y. H. (2002) Bleeding risks of antithrombotic therapy. BMJ 325, 828-831.

Franchini, M., Liumbruno, G. M., Bonfanti, C. and Lippi, G. (2016) The evolution of anticoagulant therapy. Blood Transfus. 14, 175-184.

Fung, E., Patsopoulos, N. A., Belknap, S. M., O'Rourke, D. J., Robb, J. F., Anderson, J. L., Shworak, N. W. and Moore, J. H. (2012) Effect of genetic variants, especially CYP2C9 and VKORC1, on the pharmacology of warfarin. Semin. Thromb. Hemost. 38, 893-904.

Gandhi, N. S. and Mancera, R. L. (2010) Heparin/heparan sulphatebased drugs. Drug Discov. Today 15, 1058-1069.

Garcia, D. A., Baglin, T. P., Weitz, J. I. and Samama, M. M. (2012) Parenteral anticoagulants: antithrombotic therapy and prevention of thrombosis, 9th ed: American college of chest physicians evidence-based clinical practice guidelines. Chest 141, e24S-e43S.

Greinacher, A., Thiele, T. and Selleng, K. (2015) Reversal of anticoagulants: an overview of current developments. Thromb. Haemost. 113, 931-942.

Hagedorn, I., Schmidbauer, S., Pleines, I., Kleinschnitz, C., Kronthaler, U., Stoll, G., Dickneite, G. and Nieswandt, B. (2010) Factor XIla inhibitor recombinant human albumin Infestin-4 abolishes occlusive arterial thrombus formation without affecting bleeding. Circulation 121, 1510-1517.

Hardy, S., Schirm, S., Liu, X. and Dai, Y. (2006) Tifacogin increases bacterial clearance from blood. Crit. Care 10, P155.

Heit, J. A., Spencer, F. A. and White, R. H. (2016) The epidemiology of venous thromboembolism. J. Thromb. Thrombolysis 41, 3-14.

Hirsh, J. (1991) Heparin. N. Engl. J. Med. 324, 1565-1574.

Hirsh, J. (1998) Low-molecular-weight heparin. Circulation 98, 15751582.

Hirsh, J., Fuster, V., Ansell, J. and Halperin, J. L. (2003) American heart association/American college of cardiology foundation guide to warfarin therapy. J. Am. Coll. Cardiol. 41, 1633-1652.

Hirsh, J., O'Donnell, M. and Eikelboom, J. W. (2007) Beyond unfractionated heparin and warfarin: current and future advances. Circulation 116, 552-560.

Hirsh, J. and Fuster, V. (1994) Guide to anticoagulant therapy. Part I: heparin. Circulation. 89, 1449-1468.

Hirsh, J. and Raschke, R. (2004) Heparin and low-molecular-weight heparin: The seventh ACCP conference on antithrombotic and thrombolytic therapy. Chest 126, 188S-203S.

Holmer, E., Söderberg, K., Bergqvist, D. and Lindahl, U. (1986) Heparin and its low molecular weight derivatives: Anticoagulant and antithrombotic properties. Haemostasis 16 Suppl 2, 1-7.

Hoppensteadt, D., Walenga, J. M., Fareed, J. and Bick, R. L. (2003) Heparin, low-molecular-weight heparins, and heparin pentasaccharide: Basic and clinical differentiation. Hematol. Oncol. Clin. North Am. 17, 313-341.

Howard, E. L., Becker, K. C. D., Rusconi, C. P. and Becker, R. C. (2007) Factor IXa inhibitors as novel anticoagulants. Arterioscler. Thromb. Vasc. Biol. 27, 722-727.

Hu, T. Y., Vaidya, V. R. and Asirvatham, S. J. (2016) Reversing anticoagulant effects of novel oral anticoagulants: Role of ciraparantag, andexanet alfa, and idarucizumab. Vasc. Health Risk Manag. 12, 35-44.

Hyers, T. M. (1999) Venous thromboembolism. Am. J. Respir. Crit. 
Care Med. 159, 1-14.

Kearon, C., Comp, P., Douketis, J., Royds, R., Yamada, K. and Gent, M. (2005) Dose-response study of recombinant human soluble thrombomodulin (ART-123) in the prevention of venous thromboembolism after total hip replacement. J. Thrombo Haemost. 3 , 962-968.

Kim, J. H., Lee, J., Kang, S., Moon, H., Chung, K. H. and Kim, K. R. (2016) Antiplatelet and antithrombotic effects of the extract of lindera obtusiloba leaves. Biomol. Ther. (Seoul) 24, 659-664.

Koster, A., Fischer, K. G., Harder, S. and Mertzlufft, F. (2007) The direct thrombin inhibitor argatroban: a review of its use in patients with and without HIT. Biologics 1, 105-112.

Kreimann, M., Brandt, S., Krauel, K., Block, S., Helm, C. A., Weitschies, W., Greinacher, A. and Delcea, M. (2014) Binding of anti-platelet factor 4/heparin antibodies depends on the thermodynamics of conformational changes in platelet factor 4. Blood 124, 2442-2449.

Krishnaswamy, A., Lincoff, A. M. and Cannon, C. P. (2010) The use and limitations of unfractionated heparin. Crit. Pathw. Cardiol. 9, $35-40$.

Kwon, I. S., Yim, J. H., Lee, H. K. and Pyo, S. (2016) Lobaric acid inhibits VCAM-1 expression in TNF-alpha-stimulated vascular smooth muscle cells via modulation of NF-kappaB and MAPK signaling pathways. Biomol. Ther. (Seoul) 24, 25-32.

Laterre, P. F., Opal, S. M., Abraham, E., LaRosa, S. P., Creasey, A. A., Xie, F., Poole, L. and Wunderink, R. G. (2009) A clinical evaluation committee assessment of recombinant human tissue factor pathway inhibitor (tifacogin) in patients with severe community-acquired pneumonia. Critic. Care 13, R36.

Lee, C. J. and Ansell, J. E. (2011) Direct thrombin inhibitors. Br. J. Clin Pharmacol. 72, 581-592.

Lee, D. H., Kim, H. H., Lim, D. H., Kim, J. L. and Park, H. J. (2015) Effect of cordycepin-enriched WIB801C from cordyceps militaris suppressing fibrinogen binding to glycoprotein Ilb/llla. Biomol. Ther. (Seoul) 23, 60-70.

Lenting, P. J., van Mourik, J. A. and Mertens, K. (1998) The life cycle of coagulation factor VIII in view of its structure and function. Blood 92, 3983-3996.

Liaw, P. C., Becker, D. L., Stafford, A. R., Fredenburgh, J. C. and Weitz, J. I. (2001) Molecular basis for the susceptibility of fibrinbound thrombin to inactivation by heparin cofactor II in the presence of dermatan sulfate but not heparin. J. Biol. Chem. 276 20959-20965.

Linkins, L. A., Choi, P. T. and Douketis, J. D. (2003) Clinical impact of bleeding in patients taking oral anticoagulant therapy for venous thromboembolism: A meta-analysis. Ann. Intern. Med. 139, 893900

Loke, C., Ali, S. S. and Johari, V. (2012) Pharmacology of anticoagulants. Dis. Mon. 58, 424-430.

Lurie, Y., Loebstein, R., Kurnik, D., Almog, S. and Halkin, H. (2010) Warfarin and vitamin $\mathrm{K}$ intake in the era of pharmacogenetics. $\mathrm{Br}$. J. Clin. Pharmacol. 70, 164-170.

Majeed, A. and Schulman, S. (2013) Bleeding and antidotes in new oral anticoagulants. Best Pract. Res. Clin. Haematol. 26, 191-202.

Mann, K. G., Brummel, K. and Butenas, S. (2003) What is all that thrombin for? J. Thromb. Haemost. 1, 1504-1514.

Marmur, J. D. (2002) Direct versus indirect thrombin inhibition in percutaneous coronary intervention. J. Invasive Cardiol. 14 Suppl B, 8B-18B.

Masuko, S. and Linhardt, R. J. (2012) Chemoenzymatic synthesis of the next generation of ultralow MW heparin therapeutics. Future Med. Chem. 4, 289-296.

Matyal, R., Mahmood, F. and Park, K. W. (2005) Tifacogin, recombinant tissue factor pathway inhibitor. Int. Anesthesiol. Clin. 43, 135144

Mega, J. L. and Simon, T. (2015) Pharmacology of antithrombotic drugs: an assessment of oral antiplatelet and anticoagulant treatments. Lancet 386, 281-291.

Mekaj, Y. H., Mekaj, A. Y., Duci, S. B. and Miftari, E. I. (2015) New oral anticoagulants: their advantages and disadvantages compared with vitamin $\mathrm{K}$ antagonists in the prevention and treatment of patients with thromboembolic events. Ther. Clin. Risk Manag. 11, 967-977.
Merli, G. J. and Groce, J. B. (2010) Pharmacological and clinical differences between low-molecular-weight heparins: Implications for prescribing practice and therapeutic interchange. P. T. 35, 95-105.

Miller, C. S., Grandi, S. M., Shimony, A., Filion, K. B. and Eisenberg, M. J. (2012) Meta-analysis of efficacy and safety of new oral anticoagulants (dabigatran, rivaroxaban, apixaban) versus warfarin in patients with atrial fibrillation. Am. J. Cardio. 110, 453-460.

Nawarskas, J. J. and Anderson, J. R. (2001) Bivalirudin: A new approach to anticoagulation. Heart Dis. 3, 131-137.

Park, J. M., Chang, K. H., Park, K. H., Choi, S. J., Lee, K., Lee, J. Y., Satoh M., Song S. Y. and Lee, M. Y. (2016) Differential effects between cigarette total particulate matter and cigarette smoke extract on blood and blood vessel. Toxicol. Res. 32, 353-358.

Pempe, E. H., Xu, Y., Gopalakrishnan, S., Liu, J. and Harris, E. N. (2012) Probing structural selectivity of synthetic heparin binding to stabilin protein receptors. J. Biol. Chem. 287, 20774-20783.

Perzborn, E., Roehrig, S., Straub, A., Kubitza, D. and Misselwitz, F. (2011) The discovery and development of rivaroxaban, an oral, direct factor Xa inhibitor. Nat. Rev. Drug Discov. 10, 61-75.

Piazza, G. and Goldhaber, S. Z. (2010) Venous thromboembolism and atherothrombosis: an integrated approach. Circulation 121, 21462150.

Previtali, E., Bucciarelli, P., Passamonti, S. M. and Martinelli, I. (2011) Risk factors for venous and arterial thrombosis. Blood Transfus. 9, 120-138.

Puurunen, M. K., Gona, P. N., Larson, M. G., Murabito, J. M., Magnani, J. W. and O'Donnell, C. J. (2016) Epidemiology of venous thromboembolism in the framingham heart study. Thromb. Res. 145, 27-33.

Rauova, L., Poncz, M., McKenzie, S. E., Reilly, M. P., Arepally, G., Weisel, J. W., Nagaswami, C., Cines, D. B. and Sachais, B. S. (2005) Ultralarge complexes of PF4 and heparin are central to the pathogenesis of heparin-induced thrombocytopenia. Blood 105, 131-138.

Rauova, L., Zhai, L., Kowalska, M. A., Arepally, G. M., Cines, D. B. and Poncz, M. (2006) Role of platelet surface PF4 antigenic complexes in heparin-induced thrombocytopenia pathogenesis: diagnostic and therapeutic implications. Blood 107, 2346-2353.

Roser-Jones, C., Chan, M., Howard, E. L., Becker, K. C., Rusconi, C. P. and Becker, R. C. (2011) Factor IXa as a target for pharmacologic inhibition in acute coronary syndrome. Cardiovasc. Ther. 29 e22-e35.

Ruiz, F. A., Lea, C. R., Oldfield, E. and Docampo, R. (2004) Human platelet dense granules contain polyphosphate and are similar to acidocalcisomes of bacteria and unicellular eukaryotes. J. Biol. Chem. 279, 44250-44257.

Ruppert, A., Lees, M. and Steinle, T. (2010) Clinical burden of venous thromboembolism. Curr. Med. Res. Opin. 26, 2465-2473.

Rupprecht, H. J. and Blank, R. (2010) Clinical pharmacology of direct and indirect factor Xa inhibitors. Drugs 70, 2153-2170.

Schmid, P., Fischer, A. G. and Wuillemin, W. A. (2009) Low-molecularweight heparin in patients with renal insufficiency. Swiss Med. Wkly 139, 438-452.

Schroeder, M., Hogwood, J., Gray, E., Mulloy, B., Hackett, A. M. and Johansen, K. B. (2011) Protamine neutralisation of low molecular weight heparins and their oligosaccharide components. Anal. Bioanal. Chem. 399, 763-771.

Short, N. J. and Connors, J. M. (2014) New oral anticoagulants and the cancer patient. Oncologist 19, 82-93.

Sie, P. (2016) Spotlight on idarucizumab and its potential for the reversal of anticoagulant effects of dabigatran. Drug Des. Devel. Ther. 10, 1683-1689.

Smith, S. A., Choi, S. H., Collins, J. N., Travers, R. J., Cooley, B. C. and Morrissey, J. H. (2012) Inhibition of polyphosphate as a novel strategy for preventing thrombosis and inflammation. Blood 120 , 5103-5110.

Smith, S. A. and Morrissey, J. H. (2008) Polyphosphate enhances fibrin clot structure. Blood 112, 2810-2816.

Stangier, J. and Clemens, A. (2009) Pharmacology, pharmacokinetics, and pharmacodynamics of dabigatran etexilate, an oral direct thrombin inhibitor. Clin. Appl. Thromb. Hemost. 15 Suppl 1, 9S$16 \mathrm{~S}$.

Teitel, J. M. and Rosenberg, R. D. (1983) Protection of factor Xa from 
neutralization by the heparin-antithrombin complex. J. Clin. Invest. 71, 1383-1391.

Tollefsen, D. M., Majerus, D. W. and Blank, M. K. (1982) Heparin cofactor II. Purification and properties of a heparin-dependent inhibitor of thrombin in human plasma. J. Biol. Chem. 257, 2162-2169.

Tran, H. A., Chunilal, S. D., Harper, P. L., Tran, H., Wood, E. M. and Gallus, A. S. (2013) An update of consensus guidelines for warfarin reversal. Med. J. Aust. 198, 198-199.

Travers, R. J., Shenoi, R. A., Kalathottukaren, M. T., Kizhakkedathu, J. N. and Morrissey, J. H. (2014) Nontoxic polyphosphate inhibitors reduce thrombosis while sparing hemostasis. Blood 124, 31833190.

Vavalle, J. P. and Cohen, M. G. (2012) The REG1 anticoagulation system: A novel actively controlled factor IX inhibitor using RNA aptamer technology for treatment of acute coronary syndrome. Future Cardiol. 8, 371-382.

Verhamme, P., Pakola, S., Jensen, T. J., Berggren, K., Sonesson, E., Saint-Remy, J. M., Balchen, T., Belmans, A., Cahillane, G., Stassen, J. M., Peerlinck, K., Glazer, S. and Jacquemin, M. (2010) Tolerability and pharmacokinetics of TB-402 in healthy male volunteers. Clin. Ther. 32, 1205-1220.

Verhoef, T. I., Redekop, W. K., Daly, A. K., van Schie, R. M., de Boer, A and Maitland-van der Zee, A. H. (2014) Pharmacogenetic-guided dosing of coumarin anticoagulants: algorithms for warfarin, acenocoumarol and phenprocoumon. Br. J. Clin. Pharmacol. 77, 626641.

Vincent, J. L., Ramesh, M. K., Ernest, D., LaRosa, S. P., Pachl, J., Aikawa, N., Hoste, E., Levy, H., Hirman, J., Levi, M., Daga, M., Kutsogiannis, D. J., Crowther, M., Bernard, G. R., Devriendt, J., Puigserver, J. V., Blanzaco, D. U, Esmon, C. T, Parrillo, J. E., Guzzi, L., Henderson, S. J., Pothirat, C., Mehta, P., Fareed, J., Talwar, D.,
Tsuruta, K., Gorelick, K. J., Osawa, Y. and Kaul, I. (2013) A randomized, double-blind, placebo-controlled, Phase $2 \mathrm{~b}$ study to evaluate the safety and efficacy of recombinant human soluble thrombomodulin, ART-123, in patients with sepsis and suspected disseminated intravascular coagulation. Crit. Care Med. 41, 2069-2079.

Vlasuk, G. P. and Rote, W. E. (2002) Inhibition of factor VIla/tissue factor with nematode anticoagulant protein $\mathrm{c} 2$ : from unique mechanism to a promising new clinical anticoagulant. Trends Cardiovasc. Med. 12, 325-331.

Walenga, J. M. and Lyman, G. H. (2013) Evolution of heparin anticoagulants to ultra-low-molecular-weight heparins: a review of pharmacologic and clinical differences and applications in patients with cancer. Crit. Rev. Oncol. Hematol. 88, 1-18.

Weitz, J. I. (1997) Low-molecular-weight heparins. N. Engl. J. Med. 337, 688-698.

Weitz, J. I., Hudoba, M., Massel, D., Maraganore, J. and Hirsh, J. (1990) Clot-bound thrombin is protected from inhibition by heparinantithrombin III but is susceptible to inactivation by antithrombin III-independent inhibitors. J. Clin. Invest. 86, 385-391.

Wessler, S. and Gitel, S. N. (1986) Pharmacology of heparin and warfarin. J. Am. Coll. Cardiol. 8, 10B-20B.

Wolzt, M., Weltermann, A., Nieszpaur-Los, M., Schneider, B., Fassolt, A., Lechner, K., Eichler, H. G. and Kyrle, P. A. (1995) Studies on the neutralizing effects of protamine on unfractionated and low molecular weight heparin (Fragmin) at the site of activation of the coagulation system in man. Thromb. Haemost. 73, 439-443.

Wood, J. P., Ellery, P. E., Maroney, S. A. and Mast, A. E. (2014) Biology of tissue factor pathway inhibitor. Blood 123, 2934-2943.

Yeh, C. H., Fredenburgh, J. C. and Weitz, J. I. (2012) Oral direct factor Xa inhibitors. Circ. Res. 111, 1069-1078. 